\title{
Conception, design and development of a low-cost intelligent prosthesis for one-sided transfemoral amputees
}

\author{
Wilson Carlos da Silva Júnior, Marco Aurélio Vinchi de Oliveira, Jean-Jacques Bonvent*
}

\begin{abstract}
Introduction: Modern transfemoral knee prostheses are designed to offer comfort and self-confidence to amputees. These prostheses are mainly based upon either a passive concept, with a damping system, or an active computational intelligent design to control knee motion during the swing phase. In Brazil, most lower extremity amputees are unable to afford modern prostheses due to their high cost. In this work, we present the conception, design and development of a low-cost intelligent prosthesis for one-sided transfemoral amputees. Methods: The concept of the prosthesis is based on a control system with sensors for loads, which are installed on the amputee's preserved leg and used as a mirror for the movement of the prosthesis. Mechanical strength analysis, using the Finite Element Method, electromechanical tests for the sensors and actuators and verification of data acquisition, signal conditioning and data transferring to the knee prosthesis were performed. Results: The laboratory tests performed showed the feasibility of the proposed design. The electromechanical concept that was used enabled a controlled activation of the knee prosthesis by the two load cells located on the shoe sole of the preserved leg. Conclusions: The electromechanical design concept and the resulting knee prosthesis show promising results concerning prosthesis activation during walking tests, thereby showing the feasibility of a reduced manufacturing cost compared to the modern prostheses available on the market. Keywords: Rehabilitation, Transfemoral amputees, Intelligent prostheses.
\end{abstract}

\section{Introduction}

The number of people with lower extremity amputations has significantly increased in Brazil over the past decades. Automobile accidents and diabetes mellitus are considered the main causes for these amputations (Moss et al., 1992; Trautner et al., 1996). Although very little statistical data are available regarding lower extremity amputees that need any type of rehabilitation equipment, most of these people cannot afford modern prostheses that minimize discomfort and improve quality of life.

One of the prior powered prosthetics for above-knee amputees was based on an electro-hydraulically actuated knee joint (Flowers and Mann, 1977; Grimes et al., 1977). In this design, an echo control from the intact leg was used for the gait control of the powered knee. Two examples of the above-knee powered prosthetic are the Belgrade leg and the Waseda leg (Popović et al., 1991). Popović and Schwirtlich subsequently used the technique of dynamic programming to develop an active knee that was powered by DC motors and based on position tracking for optimal gait control (Popović et al., 1995, 1999).

Actual above-knee prostheses may be classified as either non-microprocessor or intelligent, of which several are available on the market. Passive or variable-damping knee prostheses are based on a mechanical hinge with speed and ease of swing controlled by the following mechanisms: free swing, manual lock, constant friction, weight-activated friction, geometric locking and hydraulics. The passive mechanisms do not require any external power source and are less adaptive to ground level or gait speed.

Recent advances in biomedical engineering have led to the construction of intelligent prostheses that can be electronically adjusted for individual subjects. By utilizing specific programs and sensor information, these prostheses may result in a more natural gait (Aaron et al., 2006; Sup et al., 2008; Herr and Wilkenfeld, 2003; Johansson et al., 2005; Kahle et al., 2008; Kapti and Yucenur, 2006; Laferrier and Gailey, 2010). The main differences in the design of these prostheses are in their damping systems because an adequate damping allows for fast transitions in stride velocity, which increases the autonomy of the amputee. There are three main types of damping systems: passive, semi-active and active.

The microprocessor controls the velocity and the stability with which the knee swings during the swing phase. These prosthetic knees are based on programmable sensors that detect the angular 
position of the knee throughout the gait cycle and send an input signal to the prosthetic knee. In some cases, the control system allows the prosthesis to adapt in response to different walking speeds and ground conditions.

Unilateral amputees have frequently reported that variable-damping prostheses offer less muscle fatigue and smoother movement when compared with other prostheses with mechanical passive damping (Buckley et al., 1997; Datta and Howitt, 1998). Utilizing a questionnaire, Kahle et al. (2008) showed that subjects who use the hydraulic-based C-leg (commercialized by Otto Bock HealthCare Deutschland, Duderstadt, Germany) demonstrated an improved performance and higher quality of life compared to subjects who use nonmicroprocessor above-knee prostheses. Johansson et al. (2005) reported a clinical comparison between two variable-damping above-knee prostheses (the hydraulic-based C-leg and magneorheological-based Ossur Rheo) and a passive mechanism (hydraulic-based Mauch SNSC). They showed several advantages of using the Rheo compared to the Mauch, including a decrease in metabolic rate by $5 \%$ in addition to biomechanical advantages of smoother gait, decreased hip work production and lower peaks for hip flexion at terminal stance and for power generation at toe-off.

Therefore, it can be stated that microcontrolled intelligent prostheses improve damping performance as a function of the stride velocity transition, with a reduction in oxygen consumption during walking, over a wide range of velocities (Datta et al., 2005; Johansson et al., 2005; Kahle et al., 2008; Schmalz et al., 2002; Taylor et al., 1996).

However, the cost of intelligent prostheses remains too expensive because they have a high aggregated cost due to the high-end technology used. Despite all of the positive effects and benefits of microprocessor-controlled prosthetic knees, such as C-Leg (Otto Bock), on gait speed, energy consumption and cognitive performance, resulting in a good quality of life for subjects, the cost is quite high (Brodtkorb et al., 2008). For most Brazilian families and the public health system, such expensive prostheses are unaffordable.

As a result, since 1990, the Brazilian government (Secretary of Science, Technology and Strategic Resources of the Ministry of Health) has encouraged multidisciplinary research groups to focus on the development of new technologies to improve the quality of life of amputees at an affordable cost. It is worth mentioning that a cost-effectiveness analysis has to be rigorously conducted for health care resource allocation by any government (Eichler et al., 2004), especially for emerging and poor countries.
In summary, two main reasons justify the research in the development of low cost prosthetics: (a) the aging population and the subsequent increase in degenerative diseases that result in amputations and (b) the large number of Brazilian amputees that rely exclusively on the public health care system for rehabilitation (similar to many underdeveloped countries). Therefore, it is worthwhile to develop cost-effective prostheses to support the rehabilitation of amputees that rely exclusively on the public health care system. It is also our purpose to grant the use of the final product to the Brazilian public health care system and other nonprofit institutions that help and support amputees in their rehabilitation.

In this paper, we present the conception, design and development of a cost-effective intelligent prosthesis for unilateral transfemoral amputees.

\section{Methods}

The conception, design and development of the powered knee prosthesis for unilateral transfemoral amputees is described in the present work by following the design methodology steps proposed by Norton (2004).

The prosthesis is designed to be based on a simple geometry and as lightweight as possible. All mechanical components were selected based on their abundant availability in the national market, to ensure that the maintenance and parts repair and replacement are easy and cost-effective. In addition, the system was proposed to work with affordable energy consumption.

The main mechanical subsystem of the prosthesis is knee articulation. This mechanism is active based on a microcontrolled micromotor (with an embedded 1:20 rotation reduction gear train) with a worm gear pair. Because only some gear teeth are in contact when they wear or crack, the gears should be rotated and remounted to increase the durability of the system. The mechanical system of the ankle is passive and based on a five-link mechanism and a helicoidal spring that absorbs shocks and acts as a returning system.

To optimize the materials selected and the shape for the structural parts of the knee and foot prosthesis, a mechanical strength analysis was conducted using the Finite Element Method (FEM).

The stress analysis of the main knee and leg parts was performed using the computer aided engineering (CAE) software ABAQUS ${ }^{\circledast}$ (licensed by Fundação Salvador Arena), which is a dedicated multipurpose FEM package. The ankle and foot parts have small geometric details that jeopardized the import process and mesh generation in $\mathrm{ABAQUS}^{\circledR}$; therefore, these 
parts were analyzed within the native FEM code available using SolidWorks ${ }^{\circledR}$.

The geometric design was constructed using computer-aided design (CAD). SolidWorks ${ }^{\circledR}$ software (licensed by Fundção Salvador Arena) was used to simulate the stresses developed in the component parts of the prosthesis. The simulation was performed considering individuals with three different body masses: $90 \mathrm{~kg}, 85 \mathrm{~kg}$ or $70 \mathrm{~kg}$. Figure 1 shows 3D views of the complete assembly of the prosthesis, with an emphasis on the main parts of the knee articulation.

To analyze the ankle joint, it was considered that the load was articulated about two points on the extremities and the drive spring. To simulate the feet, two distinct parts were considered, the front and rear portions, and a system of coordinates $\mathrm{X}, \mathrm{Y}$ and $\mathrm{Z}$ that was used for the precise localization of the results.

The control system of the prosthesis is based on the amputee's preserved leg. In level-ground walking, the normal gait cycle can be divided into two main phases, the stance and swing phases, when the foot is in contact with the ground and in the air, respectively. The stance phase corresponds to approximately $60 \%$ of the gait cycle, while the swing phase is the remaining 40\% (Kadaba et al., 1990; Kapti and Yucenur, 2006; Martinez-Villalpando and Herr, 2009).

An intelligent data acquisition system, based on sensors for loads, was installed on the amputee's preserved leg, which is used as a mirror (or pantograph) for the movement of the prosthesis. To detect the two different gait phases for the prosthesis activation, two load cells are installed on the shoe sole of the preserved leg, and an angular position sensor is installed on the prosthetic knee.

The loads used to calculate the stresses in the components were based on the pioneering study of Jonh P. Paul concerning the force transmitted in the human body during walking (Paul, 1971). To account for a more realistic Brazilian body type and to include a safety factor to the stresses, the original loads reported by Paul were scaled to a $90 \mathrm{~kg}$ male subject of $1.83 \mathrm{~m}$ height and a walking velocity of approximately $2.1 \mathrm{~m} / \mathrm{s}$.

The prosthesis system is controlled by a microcontroller model Microchip ${ }^{\circledR}$ PIC18F452 that acquires data from the pressure sensors and the angular sensor located on the prosthesis. This microcontroller displays the data on an alphanumerical LCD display and interfaces with the computer via RS232. The microcontroller, basically composed of an integrated L298 circuit, provides signals to control the driver of the prosthesis's motor.

Figure 2 shows a flowchart of the block diagram of the control system. The main digital circuits used for the DC motor (H-bridge driver) control and for the load cells' signal processing are presented in Figure 3 . The microcontroller used is a model $18 \mathrm{~F} 425$, with 8 10-bit analog input channels. To verify the sensors' signals, an LCD display is used.

\section{Results}

The stress contour plot and analysis results of the different parts of the prosthesis, i.e., in the prosthetic socket, the structural parts, and top and bottom parts of the artificial foot, are presented in Figure 4. Critical stresses in the parts for the conditions analyzed are below $90 \mathrm{MPa}$. Based on the stress results, the material selected for the structural parts was the aluminum alloy AA5052-H32 (hardness HB60, 193 MPa yielding
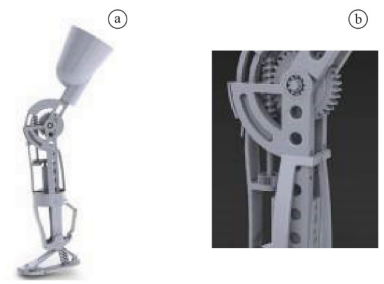

(b)

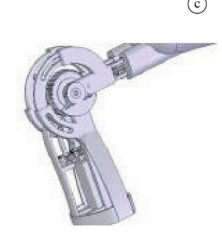

Figure 1. (a) 3D views of the above-knee prosthesis with (b) and (c) details of the knee components.

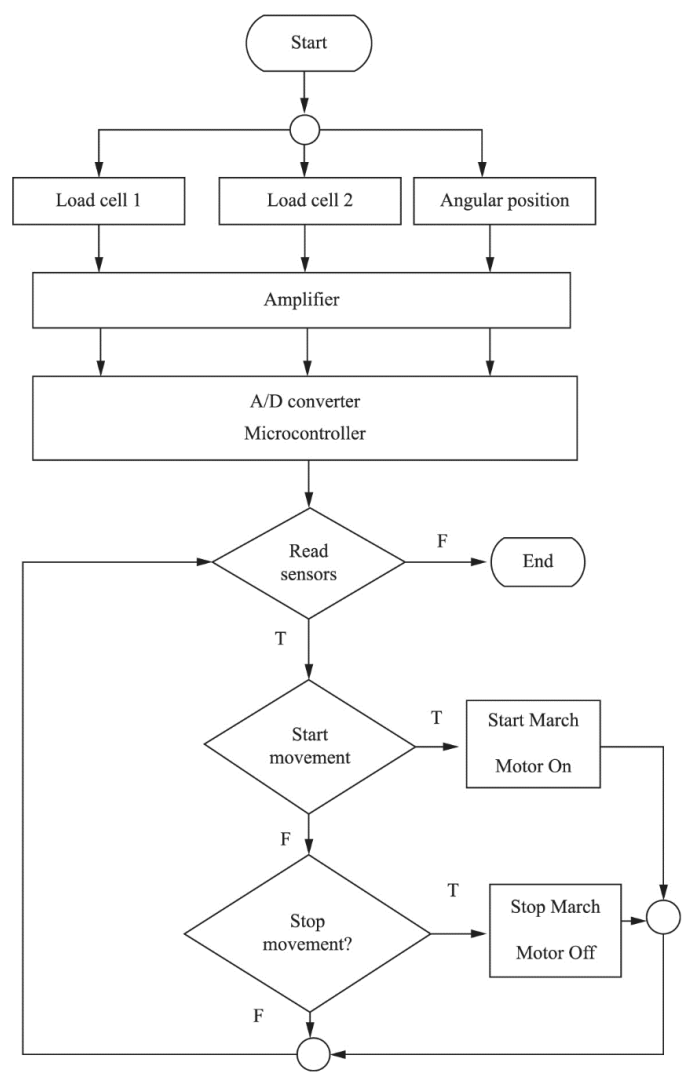

Figure 2. Flowchart with the block diagram of the prosthesis control system. 


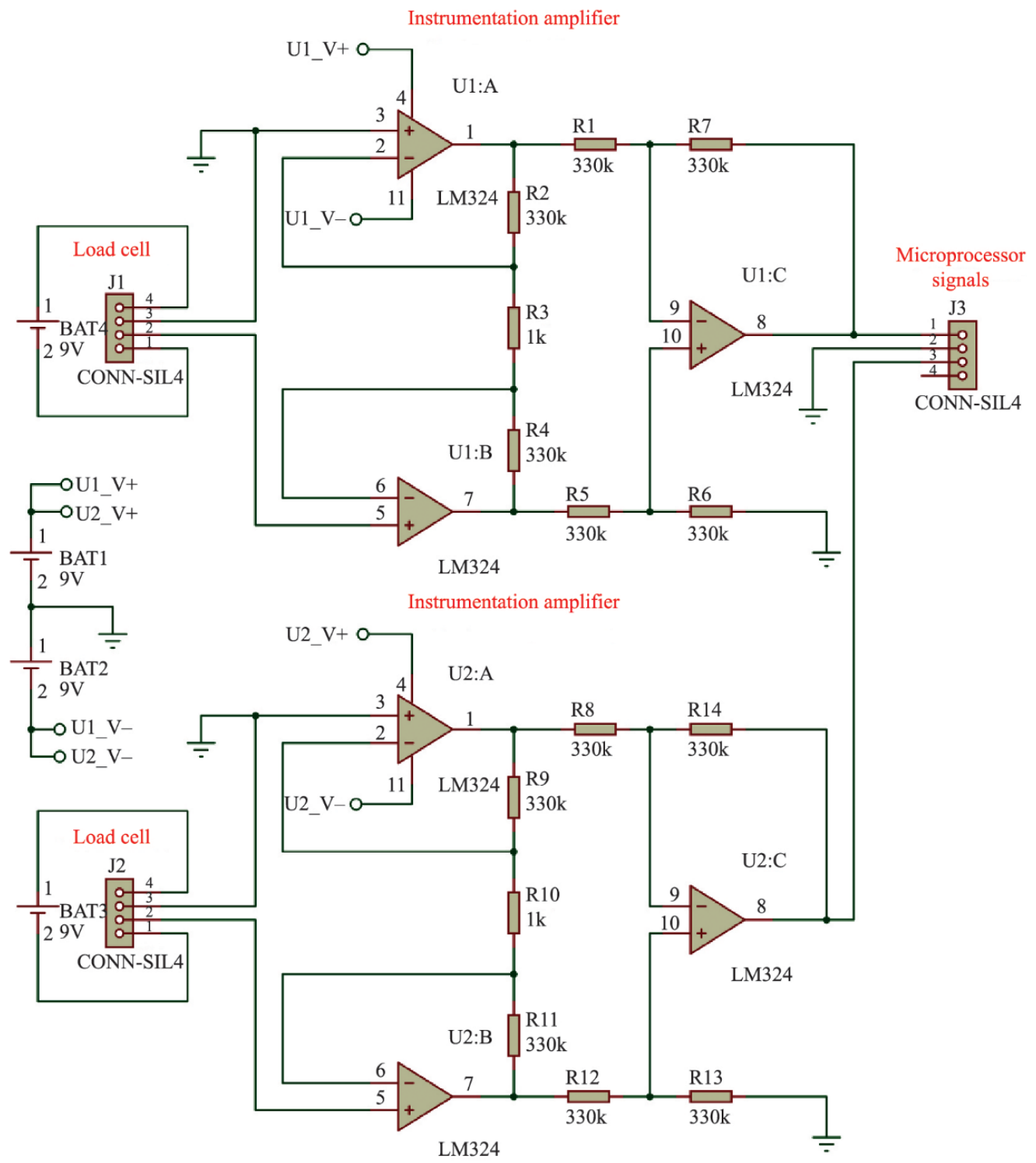

Figure 3. Analog front-end circuit for the load cells.

limit, $228 \mathrm{MPa}$ ultimate stress limit and $117 \mathrm{MPa}$ fatigue limit at $5 \times 10^{8}$ cycles). Other material alloys, such as stainless steel or titanium, should also be considered for this application, but the cost could be a limiting factor.

The load cells were built from strain gauges embedded inside of aluminum pieces $(20 \mathrm{~mm}$ and $50 \mathrm{~mm}$ diameter) (Figures $5 \mathrm{a}$ and $5 \mathrm{~b}$ ) and installed bellow the hallux and the heel (Figure 5c), respectively, which correspond to the regions of higher pressure in the foot sole during the gait phases (Kljajić and Krajnik, 1987; Liedtke et al., 2007; Wearing et al., 1999). The electrical signals from these sensors were treated in an instrumentation circuit using operational amplifiers and then connected to the microcontroller.
The angular sensor fixed on the knee prosthesis consists of a potentiometer connected to the microcontroller, which allows for the monitoring of the angular position during the flexion and extension movements.

A micromotor through an $\mathrm{H}$-bridge driver circuit activates the knee movement of the prosthesis. The nominal micromotor specifications are 12 VDC voltage, $4300 \mathrm{rpm}$ rotation speed, $330 \mathrm{~mA}$ of current, $1.8 \mathrm{~W}$ of output power and a torque of $40 \mathrm{~g} . \mathrm{cm}$. The micro-motor is equipped with a 1:20 reduction system.

To check the main system characteristics and performance, a prototype was constructed. The different parts of the prosthesis were machined 

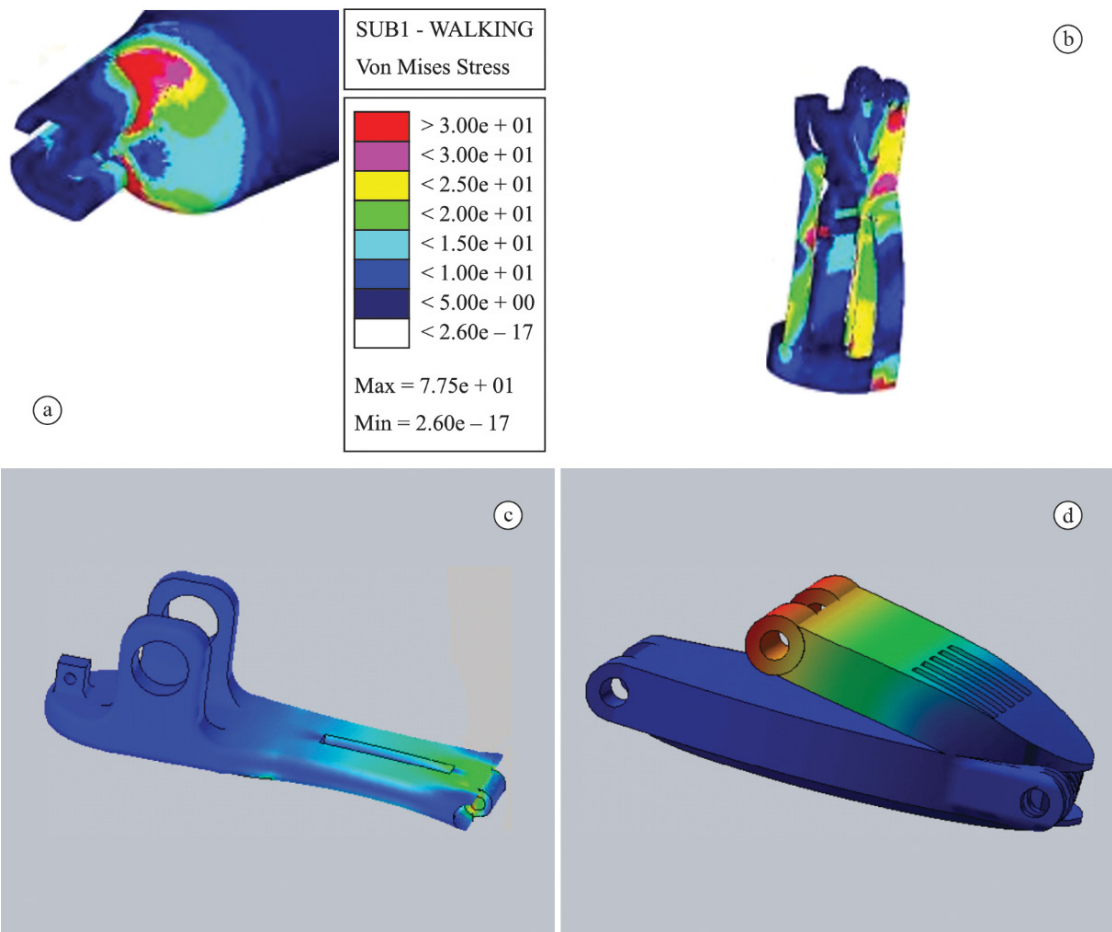

Figure 4. Stress contour plots of the different components analyzed. Stresses in the (a) prosthetic socket, (b) structural parts, (c) bottom part of the foot and (d) upper part of the artificial foot.
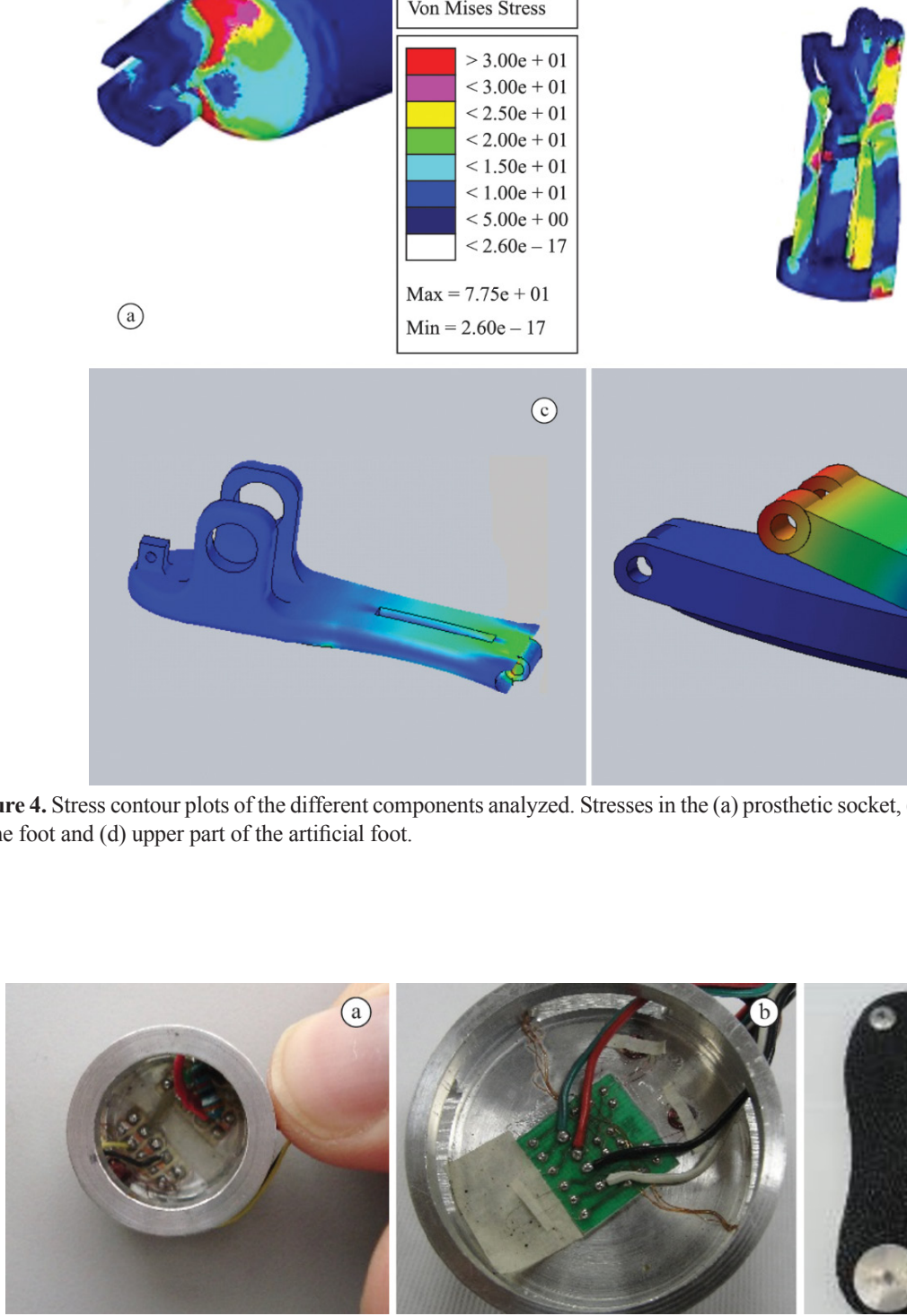

igure 5. Load cells: (a) $20 \mathrm{~mm}$ and (b) $50 \mathrm{~mm}$ diameter. (c) Load cells installed on the shoe sole below the hallux and the heel.

using a Computer Numerical System (CNC system). Figure 6 shows the mounted artificial knee and foot. The performance of the prosthesis components was analyzed using multiple devices, as shown in Figure 6. At this stage in the design, no tests with transfemoral amputees have been performed.

The activation of the prosthesis was analyzed in terms of the pressure on the load cells and the angular position displayed by the potentiometric sensor. Ten trials were conducted simulating slow walking, with each trial consisting of six consecutive walking steps. Phase gait duration was not taken into consideration, instead focusing on the synchronization and the time to drive the prosthesis by the signals from the pressure sensors. To analyze the prosthesis activation response, the step data from the pressure and angular position sensors were stored using a home-built data acquisition system for posterior plotting and analysis.

Figures 7 and 8 show the experimental curves obtained for the load cells response during gait, plotted together with the corresponding angular position of the knee prosthesis.

It can be observed that the load cells' response during the preserved leg extension and flexion showed 


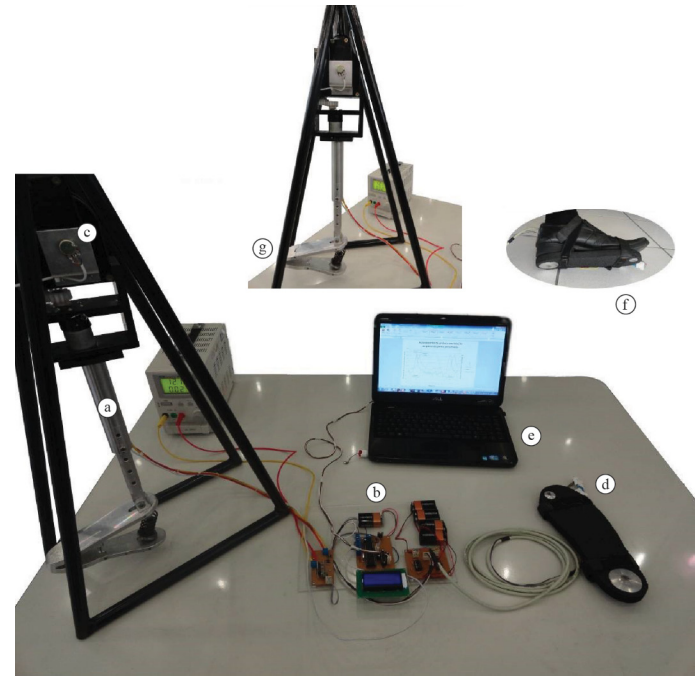

Figure 6. System to test the prosthesis components, including the artificial limb (a), the control system (b), the angular sensor (c), the shoe sole containing the load cells (d) and the computer for data storage and analyses (e). The enclosed figure (f) shows the fixation of the sole for the tests, and the enclosed figure $(\mathrm{g})$ is the view of the knee system with the angular sensor.

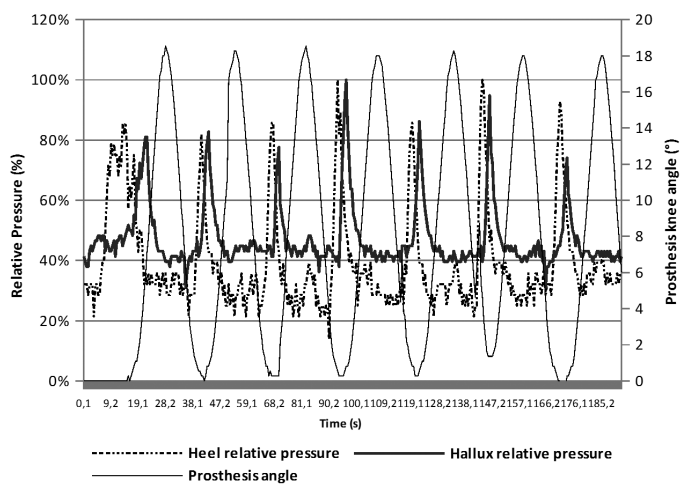

Figure 7. Experimental curves of the variation of the heel and hallux relative pressure during gait, plotted together with the induced prosthesis knee angle.

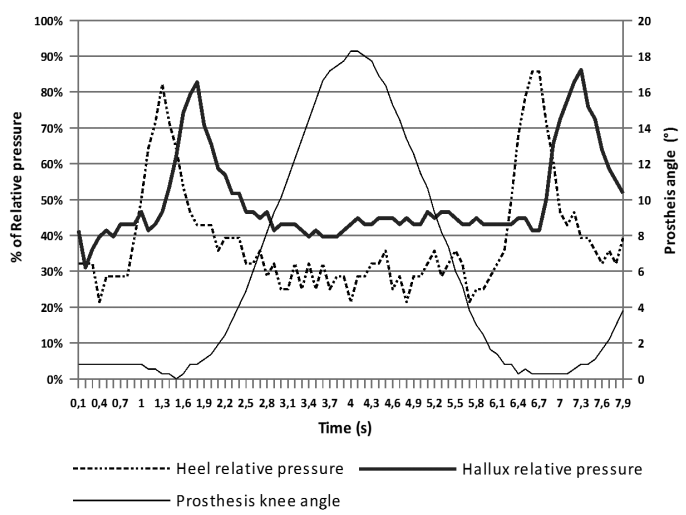

Figure 8. Experimental curves of the variation of the heel and hallux relative pressures during one step motion, plotted together with the induced prosthesis knee angle. that the detected signals correspond to the expected foot contact areas sequence, i.e., the heel followed by the hallux, with the corresponding relative pressures. As soon as the hallux of the preserved leg starts to lose contact with the sole, the angular position of the prosthetic knee increases up to a maximum value that corresponds to the maximum flexion allowed for the prosthesis, before returning to the extension position for sole contact. The synchronization for the circuitry feed of the microprocessor-controlled system is quite fast and did not show any failure during the different tests performed. The system worked smoothly, and the response time observed was adequate to provide comfort to the amputees.

\section{Discussion}

This work presented the conception, design and development of an intelligent, low-cost prosthesis for one-sided transfemoral amputees.

Several simulations and tests were performed, including mechanical strength analysis to select materials for the structural components through the Finite Element Method, electromechanical tests for the calibration of the sensors and actuators and tests of the electronic circuits for verification of data acquisition, signal conditioning and data transfer to the knee prosthesis.

The experimental tests for the activation of the knee prosthesis, in terms of the dynamic response during flexion and extension during a slow walk, showed results consistent with the required features of the prosthesis. Of these features, the prosthesis achieved a good correlation between angular position of the prosthetic knee joint and the foot sole contact pressure of the preserved leg. In the present study, only two contact areas of the sole were considered for the activation of the flexion and extension of the knee prosthesis. This approach to monitoring the sound leg ground reaction, also referred to as "echo control", as a control signal for the above-knee prosthesis was first reported by Flowers and Mann (1977), Grimes et al. (1977) and Bar et al. (1983). More recently, Joshi et al. (2010) and Vallery et al. (2011) used a similar system. The "Power Knee", which is commercialized by the Ossur Company, uses a similar echo control approach in which sensors on the sound leg are used to optimize the patient's gait.

Nevertheless, using only the preserved leg to control the above-knee flexion and extension is a simple system and has some limitations, including a lack of precise and smooth gait control for any self-selected walking speed. Most of the recent developments in gait control for above-knee prosthesis are based on instrumented shoes coupled to the prosthesis, as 
reported by Bar et al. (1983), Herr and Wilkenfeld (2003) and Kapti and Yucenur (2006). Compared to our approach, which is based on the echo control, when the load sensors are installed on the prosthesis foot, there are limitations for cyclic and symmetric patterns and the use for only unilateral amputees.

Even though the prosthesis proposed in the present work is based on a simple control mechanism, it can be classified as an intelligent powered above-knee prosthesis that be controlled by only one embedded DC motor. This is in contrast to current prosthetic controllers that are highly complex and intelligent through the use of sophisticated rules, which in turn make them more costly.

Compared to passive above-knee prostheses, the powered prostheses require a battery and associated weight and power consumption. In the present design, the power supply and the DC motor are installed inside of the prosthesis, allowing for a reduced size, as suggested by Bar et al. (1983) in the group's early work. We have also used only one DC motor, a microcontrolled micromotor, which is a more compact solution compared to other designs proposed, such as that of Kapti and Yucenur (2006) or Martinez-Villalpando and Herr (2009).

We have developed a microprocessor-powered knee prosthesis for unilateral transfemoral amputees. The prosthesis was designed to be compact and inexpensive and is based on an echo control for the preserved leg.

It was found that only two load sensors installed in an instrumented sole for the preserved leg were required to easily and smoothly activate the flexion and extension of the prosthetic knee. The electronic circuitry, including the load cells used to control the prosthesis activation and the micromotor drive, could easily be adjusted for different walking speeds and knee joint angles, thereby ensuring the safety of the transfemoral amputees.

Further research is needed to improve the system characteristics and verify if this adopted electromechanical concept could allow a reduction in the estimated manufacturing cost of the prosthesis, compared to commercially available microprocessor active prostheses. In addition, it is necessary to test the system in humans to confirm the results of the prototypes.

\section{Acknowledgements}

The authors acknowledge UMC - Universidade de Mogi das Cruzes, SP - Brazil and FAEP (Fundação de Amparo ao Ensino e Pesquisa) for providing human and educational support, material conditions and financial grants for concluding the author's doctoral degree and to finish this project. CEFSA is also acknowledged for providing time, people and infrastructure to make this project possible. Finally, CBA (Companhia Brasileira do Alumínio) is acknowledged for providing the aluminum used to construct the prosthesis prototype.

\section{References}

Aaron RK, Herr HM, Ciombor DM, Hochberg LR, Donoghue JP, Briant CL, Morgan JR, Ehrlich MG. Horizons in prosthesis development for the restoration of limb function. The Journal of the American Academy of Orthopaedic Surgeons 2006; 14(10):S198-204. PMid:17003199.

Bar A, Ishai G, Meretsky P, Koren Y. Adaptive microcomputer control of an artificial knee in level walking. Journal of Biomedical Engineering 1983; 5(2):145-50. http://dx.doi. org/10.1016/0141-5425(83)90034-1. PMid:6855215

Brodtkorb TH, Henriksson M, Johannesen-Munk K, Thidell F. Cost-effectiveness of C-leg compared with nonmicroprocessor-controlled knees: a modeling approach. Archives of Physical Medicine and Rehabilitation 2008; 89(1):24-30. http://dx.doi.org/10.1016/j.apmr.2007.07.049. PMid:18164326

Buckley JG, Spence WD, Solomonidis SE. Energy cost of walking: comparison of "intelligent prosthesis" with conventional mechanism. Archives of Physical Medicine and Rehabilitation 1997; 78(3):330-3. http://dx.doi.org/10.1016/ S0003-9993(97)90044-7. PMid:9084360

Datta D, Heller B, Howitt J. A comparative evaluation of oxygen consumption and gait pattern in amputees using Intelligent Prostheses and conventionally damped knee swing-phase control. Clinical Rehabilitation 2005; 19(4):398-403. http:// dx.doi.org/10.1191/0269215505cr805oa. PMid:15929508

Datta D, Howitt J. Conventional versus microchip controlled pneumatic swing phase control for trans-femoral amputees: user's verdict. Prosthetics and Orthotics International 1998; 22(2):129-35. PMid:9747997.

Eichler HG, Kong SX, Gerth WC, Mavros P, Jönsson B. Use of cost-effectiveness analysis in health-care resource allocation decision-making: how are cost-effectiveness thresholds expected to emerge? Value in Health 2004; 7(5):51828. http://dx.doi.org/10.1111/j.1524-4733.2004.75003.x. PMid: 15367247

Flowers WC, Mann RW. An electrohydraulic kneetorque controller for a prosthesis simulator. Journal of Biomechanical Engineering 1977; 99(1):3-8. http://dx.doi. org/10.1115/1.3426266. PMid:23720163

Grimes DL, Flowers WC, Donath M. Feasibility of an active control scheme for above knee prostheses. Journal of Biomechanical Engineering 1977; 99(4):215-21. http:// dx.doi.org/10.1115/1.3426293.

Herr H, Wilkenfeld A. User-adaptive control of a magnetorheological prosthetic knee. The Industrial Robot 2003; 30(1):42-55. http://dx.doi.org/10.1108/01439910310457706.

Johansson JL, Sherrill DM, Riley PO, Bonato P, Herr H. A clinical comparison of variable-damping and mechanically 
passive prosthetic knee devices. American Journal of Physical Medicine \& Rehabilitation 2005; 84(8):563-75. http://dx.doi.org/10.1097/01.phm.0000174665.74933.0b. PMid:16034225

Joshi D, Singh R, Ribeiro R, Srivastava S, Singh U, Anand S. Development of echo control strategy for AK prosthesis: an embedded system approach. Systems in Medicine and Biology (ICSMB). In: 2010 International Conference; 2010 Dec 16-18; Kharagpur. IEEE; 2010. p. 143-7.

Kadaba MP, Ramakrishnan HK, Wootten ME. Measurement of lower extremity kinematics during level walking. Journal of Orthopaedic Research 1990; 8(3):383-92. http://dx.doi. org/10.1002/jor.1100080310. PMid:2324857

Kahle JT, Highsmith MJ, Hubbard SL. Comparison of nonmicroprocessor knee mechanism versus C-Leg on Prosthesis Evaluation Questionnaire, stumbles, falls, walking tests, stair descent, and knee preference. Journal of Rehabilitation Research and Development 2008; 45(1):1-14. http://dx.doi. org/10.1682/JRRD.2007.04.0054. PMid:18566922

Kapti AO, Yucenur MS. Design and control of an active artificial knee joint. Mechanism and Machine Theory 2006; 41(12):1477-85. http://dx.doi.org/10.1016/j. mechmachtheory.2006.01.017.

Kljajić M, Krajnik J. The use of ground reaction measuring shoes in gait evaluation. Clinical Physics and Physiological Measurement 1987; 8(2):133-42. http://dx.doi.org/10.1088/01430815/8/2/004. PMid:3595081

Laferrier JZ, Gailey R. Advances in lower-limb prosthetic technology. Physical Medicine and Rehabilitation Clinics of North America 2010; 21(1):87-110. http://dx.doi. org/10.1016/j.pmr.2009.08.003. PMid:19951780

Liedtke C, Fokkenrood SA, Menger JT, van der Kooij H, Veltink PH. Evaluation of instrumented shoes for ambulatory assessment of ground reaction forces. Gait \& Posture 2007; 26(1):39-47. http://dx.doi.org/10.1016/j.gaitpost.2006.07.017. PMid:17010612

Martinez-Villalpando EC, Herr H. Agonist-antagonist active knee prosthesis: a preliminary study in level-ground walking. Journal of Rehabilitation Research and Development 2009; 46(3):361-73. http://dx.doi.org/10.1682/JRRD.2008.09.0131. PMid:19675988

Moss SE, Klein R, Klein BE. The prevalence and incidence of lower extremity amputation in a diabetic population. Archives of Internal Medicine 1992; 152(3):610-6. http:// dx.doi.org/10.1001/archinte.1992.00400150120022. PMid: 1546925
Norton RL. Machine design: an integrated approach. 2. ed Porto Alegre: Bookman; 2004.

Paul JP. Loads action in the human femur in walking and some resultant stresses. Experimental Mechanics 1971; 11(3):121-5. http://dx.doi.org/10.1007/BF02328646.

Popović D, Oğuztöreli MN, Stein RB. Optimal control for an above-knee prosthesis with two degrees of freedom. Biomechanics. 1995; 28(1):89-98. http://dx.doi. org/10.1016/0021-9290(95)80010-7. PMid:7852445

Popović D, Stein RB, Oğuztöreli N, Lebiedowska M, Jonić S. Optimal control of walking with functional electrical stimulation: a computer simulation study. IEEE Transactions on Rehabilitation Engineering 1999; 7(1):69-79. http:// dx.doi.org/10.1109/86.750554. PMid:10188609

Popović D, Tomovic R, Tepavac D, Schwirtlich L. Control aspects of active above knee prosthesis. International Journal of Man-Machine Studies 1991; 35(6):751-67. http://dx.doi. org/10.1016/S0020-7373(05)80159-2.

Schmalz T, Blumentritt S, Jarasch R. Energy expenditure and biomechanical characteristics of lower limb amputee gait: the influence of prosthetic alignment and different prosthetic components. Gait \& Posture 2002; 16(3):25563. http://dx.doi.org/10.1016/S0966-6362(02)00008-5. PMid:12443950

Sup F, Bohara A, Goldfarb M. Design and control of a powered transfemoral prosthesis. The International Journal of Robotics Research 2008; 27(2):263-73. http://dx.doi. org/10.1177/0278364907084588. PMid:19898683

Taylor MB, Clark E, Offord EA, Baxter C. A comparison of energy expenditure by a high level trans-femoral amputee using the Intelligent Prosthesis and conventionally damped prosthetic limbs. Prosthetics and Orthotics International 1996; 20(2):116-21. PMid:8876005.

Trautner C, Haastert B, Giani G, Berger M. Incidence of lower limb amputations and diabetes. Diabetes Care 1996; 19(9):1006-9. http://dx.doi.org/10.2337/diacare.19.9.1006. PMid:8875099

Vallery H, Burgkart R, Hartmann C, Mitternacht J, Riener R, Buss M. Complementary limb motion estimation for the control of active knee prostheses. Biomedizinische Technik. 2011; 56(1):45-51. http://dx.doi.org/10.1515/bmt.2010.057. PMid:21303189

Wearing SC, Urry S, Smeathers JE, Battistutta D. A comparison of gait initiation and termination methods for obtaining plantar foot pressures. Gait \& Posture 1999; 10(3):25563. http://dx.doi.org/10.1016/S0966-6362(99)00039-9. PMid:10567758

\section{Authors}

\section{Wilson Carlos da Silva Júnior ${ }^{1,2}$, Marco Aurélio Vinchi de Oliveira ${ }^{1}$, Jean-Jacques Bonvent ${ }^{3 *}$}

${ }^{1}$ Centro Educacional da Fundação Salvador Arena - CEFSA, Faculdade de Tecnologia Termomecânica - FTT, São Bernardo do Campo, SP, Brasil.

${ }^{2}$ Universidade de Mogi das Cruzes - UMC, Av. Dr. Cândido Xavier de Almeida Souza, 200, Centro Cívico, CEP 08780911, Mogi das Cruzes, SP, Brasil.

${ }^{3}$ Centro de Ciências Naturais e Humanas - CCNH, Universidade Federal do ABC - UFABC, Avenida dos Estados, 5001, Bairro Bangu, CEP 09210-580, Santo André, SP, Brasil. 